\title{
The modern interpretation of the high-flow gas wells study results
}

\author{
Nick Roy ${ }^{1 *}$, Irina Usenko ${ }^{1}$, Oleksandr Akulshyn ${ }^{2}$, and Igor Limar ${ }^{3}$ \\ ${ }^{1}$ Poltava National Technical Yuri Kondratyuk University, Oil and Gas Institute, 24 Pershotravnevyi Ave., \\ 36011, Poltava, Ukraine \\ ${ }^{2}$ JSC "Ukrainian Oil and Gas Institute", 7 Kudriavska St, 04053, Kyiv, Ukraine \\ ${ }^{3}$ RUE "Belorusneft Production Association", Core Research Laboratory of BelNIPIneft, \\ 15a Knizhnaya St, 246000, Gomel, Republic of Belarus
}

\begin{abstract}
Based on the analysis of the currently existing methods of interpreting the results of research into gas-saturated and gas-condensate formations in the case of stationary or non-stationary filtration, the direction of solving this problem is indicated specifically for high-flow wells using new calculation method. Since the method has not existed in the traditional way until now, the new one is based on an original and unconventional approach to the initial data. And the results of its application are several times higher than the results of the traditional approach to the study of gas wells with a stationary inflow. That is, the method directly affects the quantity and quality of information obtained in the study on the gashydrodynamic characteristics of the studied high-flow gas wells. It also made it possible to develop a new technological approach to well testing, which at present should be considered rational, optimal and most modern. This method and the results that it allows to obtain are given in this publication. All this taken together makes it possible to approve a successful solution to the complex and still unsolved problem of the technological and methodological plan for the study of high-flow gas wells.
\end{abstract}

\section{Introduction}

It is important for any country to have its own powerful energy base. To a large extent, this concerns the current state of the energy base of Ukraine. On the one hand, this allows to set the price of gas in the domestic market. On the other hand, it will allow the entire capacity of the gas transmission system to be used for gas transit to other consumers.

This problem can be solved in two ways. The first involves the increase in raw material potential through new exploration wells, which requires significant investment. Moreover, the return on them can be only in a few years. The second is the economical and rational use of proven reserves.

In terms of a rational approach to the use of modernized technologies, of course, preference should be given to the least costly ones that can be implemented in a short time $[1,2]$.

*Corresponding author: ongp1@ukr.net 
Given the global scientific and technological progress and the use of modern computer technology and software products, production places high demands on the volume and quality of information that form the basis for predicting the main indicators for the development of gas, gas condensate and oil fields. It is obtained thanks to gashydrodynamic well studies, which are carried out both at the exploratory stage and at the operational stage of production facilities [3, 4]. It is logical to pay special attention to scientific research aimed at developing precisely those methods with which can get the necessary information with the least effort and resources for research $[5,6]$.

\section{Literature analysis and problem statement}

Analyzing the work performed by production enterprises for the development and research of wells after they left the drilling and intensification of their work, then the average annual gas loss attributed to its annual production, have an indicator of $0.2-0.3 \%$ [7].

When gas well exploration and research takes place with the release of gas into the atmosphere, this is associated on the one hand with very significant gas losses, and on the other hand, with environmental pollution.

To illustrate the scale of such losses, is given an example when, during the study of gas wells in the traditional way, as required by the current regulatory documents, with the release of gas into the atmosphere at only 10 objects in the wells of the Abazivskoy, Matveevsky and Chutovskaya areas, 14 million 474 thousand cubic meters of gas were burned. In terms of oil, this is equivalent to about 14 thousand cubic meters of oil. For the whole country, these losses are very significant, so that they could not simply be neglected.

At the same time, if the methods is analyzed [1,3], which are now used to interpret the evidence obtained as a result of the study, it becomes clear that they are suitable specifically for traditional methods for studying gas wells $[8,9]$. That is, for the study of gas wells using 5-8 modes. Moreover, these studies relate specifically to stationary modes [10, 11].

As for the research of high flow rate wells, which are characterized by unsteady filtration, after which the pressure is immediately restored to the bottom, then by this time in domestic and world practice about the technology of their research or in 5-8 modes, in one unsteady mode, it didn't go at all.

On the other hand, individual approaches are described using well-known techniques, due to which a small number of gas-hydrodynamic parameters of such wells are determined [12]. Because of this, it is not possible to determine such a range of geological information, using which it is possible to calculate product stocks and prepare development projects for deposits. For almost half a century this problem has not been solved, but the need for its solution is undeniable.

\section{The purpose and objectives of the study}

The studies were aimed at identifying new opportunities for fragmented calculations of gas well parameters based on the data obtained through the study and, thanks to them, form a complete interpretation algorithm.

To achieve this goal, the following tasks were solved:

- establish the value of complex parameters for solving interpretation problems and apply them to the fullest extent;

- solve the problem of analytical calculation of the well radius;

- solve the problem of analytical calculation of the coefficients of porosity, permeability, effective thickness of the productive studied formation.

Solving these main tasks will provide a fundamental basis for creating a new interpretation algorithm. 


\section{Materials and research methods}

The indicated problem for today can be considered solved theoretically. The developed method for researching high-performance gas wells [13], thanks to which it is possible to investigate high-yield wells or in 5-8 non-stationary modes, in one non-stationary mode. This method can also be used to study wells in the development of gas hydrate deposits using already known technologies for converting hydrates into a gaseous state.

Along with this, a technique has been developed for servicing such a method, which provides the initial data for the study of such wells with the determination of a significant number of parameters characterizing the well-formation system. Moreover, almost all parameters are calculated analytically, which is a sign of the accuracy of their determination.

Such a technique is the result of an analysis of existing interpretation methods and their suitability for use in the case of researching precisely high-yield gas wells. It is based on the primary evidence of research on a new technology $[6,13]$ and solves the problem of not only losing valuable geological information but getting it several times more and of the highest quality.

The implementation of such a technique through a certain mathematical complexity to achieve the accuracy of the calculations should usually be set out in a software environment. This will eliminate approximate calculations using pallets (for example, the definition of Duhamel integrals). In addition to the accuracy of the calculations, another important result is achieved - reducing the time it takes to interpret the results of the study.

The methodology will allow to analytically determine 20 gas-hydrodynamic parameters of productive gas and gas condensate reservoirs, including: the equation of product inflow, porosity, permeability, piezoelectricity coefficients, skin effect - as an indicator of the reservoir opening quality, the radius of the drainage contour, effective reservoir power, like that.

According to the approach to accounting for product inflow to the bottom of the well, the methods for processing pressure recovery curves (PRC) are divided into differential, differential-integral and integral. The most accurate modern methods that are widely used in oil and gas field practice are described in $[6,13]$.

From its analysis it follows that the determination of the physical parameters of the reservoirs under unsteady filtration conditions from the curves for the restoration of bottomhole pressure, taking into account the inflow, can be carried out by several methods: the differential method Yu.P. Borisov, by the tangent method, by the integral-differential method I.A. Charnoy - I.D. Umrikhin, the integrated method of UkrSGRI.

Comparing these methods in terms of the accuracy of the results and the volume of industrial and computational work, the Ukrainian scientist A.P. Kanyugoy. It was found [3]. that the exact results in interpreting the actual data from the study of high-yield wells are given by the tangent method and the differential method of Yu.P. Borisov. It should be noted that both of these methods can be successfully used only if the pressure is restored quickly (within 10-60 minutes) after closing the well after operating it in the mode. Moreover, the method of Yu.P. Borisov requires a significant amount of computational work. But at the same time, it avoids the subjective construction of a tangent, which, in fact, can be considered a drawback of the tangent method.

When the pressure is slowly restored, when the well is closed for recording HPC, during the study cycle (from several hours to several weeks), the use of the integral-differential method of I.A. Charnoy - I.D. Umrikhin or the integrated method of UkrSGRI, developed at one time by the specialists of UkrSGRI, and the latter compares favourably with a significantly smaller amount of calculations, convenient and easy to use.

When creating a new methodology for interpreting the actual research data if the filtration of gas or gas condensate before the bottom of the well is unsteady, an integrated approach was applied based on the observance of certain principles. For example, the 
choice of a technique depended on how accurate the results of its application would be (the complexity of the technique was fading into the background), the simultaneous use of two such techniques and the use of mathematical modelling $[14,15]$ to ensure objective interpretation and its acceleration.

Two methods best meet these requirements - Yu.P. Borisov $[6,16]$ as well as the method of I.A. Charnoy [7, 17]. The results of the chosen approach were included as components in an independent technique and are reflected in the patent materials [13].

So, in the original, the calculation formula of the differential method of Yu.P. Borisov has the form:

$$
\frac{\left(P_{b o t}^{2}-P_{b o t_{0}}^{2}\right) \cdot \alpha}{2 P_{a t m}}=\frac{Q_{0}}{4 \pi \frac{k h}{\mu}}\left(\ln \frac{2.2458 c e}{r_{n}^{2}}+\ln \Theta\right),
$$

where $P_{b o t}$ - current bottomhole pressure after shutdown, Pa; $P_{b o t} 0-$ bottomhole pressure under conditions of stationary gas or gas condensate inflow before stopping the operation of the well, $\mathrm{Pa} ; P_{a t m}$-atmosphere pressure, $P_{a t m}=0.1013027 \cdot 10^{6} \mathrm{~Pa} ; \quad \alpha=\frac{Q_{0}}{Q_{0}-q(t)}$, dimensionless; $Q_{0}$ - flow rate of gas condensate mixture before stopping the operation of the well, $\mathrm{m}^{3} / \mathrm{s} ; q(t)$ - flow rate of gas condensate mixture before stopping the operation of the well, $\mathrm{m}^{3} / \mathrm{s} ; k$-formation permeability coefficient, $\mathrm{m}^{2} ; h$-effective thickness of the reservoir, $\mathrm{m} ; \mu$-dynamic viscosity of gas or gas condensate in reservoir conditions, Pa's; $a$-coefficient of reservoir piezo conductivity, $\mathrm{m}^{2} / \mathrm{s} ; r_{n}$-reduced well radius, $\mathrm{m}$; $\ln \theta-\ln t-\beta ; t$-time of observation of the restoration of reservoir pressure, $\mathrm{s}$; $\beta=\frac{1.6[\bar{q}(t)-q(t)]}{Q_{0}-q(t)}$, dimensionless; $\bar{q}(t)-$ the average flow rate of the gas condensate mixture after stopping the operation of the well, $\mathrm{m}^{3} / \mathrm{s}$.

If $\alpha$ and $\beta$ is substituted to the indicated expressions, then:

$$
\begin{gathered}
\frac{\left(P_{b o t}^{2}-P_{b o t_{0}}^{2}\right) \cdot \alpha}{Q_{0}-q(t)}=\frac{P_{a t m}}{2 \pi \frac{k h}{\mu}}\left(\ln \frac{2.2458 a}{r_{n}^{2}}+\ln \Theta\right) \\
\ln Q=\ln t-\frac{1.6[\bar{q}(t)-q(t)]}{Q_{0}-q(t)} .
\end{gathered}
$$

According to the results of processing the reservoir pressure recovery curve by the Borisov method, ascending straight lines are constructed in coordinates $x=\ln \Theta$; $y=\frac{P_{b o t}^{2}-P_{b o t_{0}}^{2}}{Q_{0}-q(t)}$ for the zone near the well and the zone far from the well of the reservoir, which has angles of inclination to the abscissa axis $\alpha_{1}$ and $\alpha_{2}$ respectively. Then the gas conductivity of the zone near the well will be $\left(\frac{k h}{\mu}\right)_{1}=\frac{P_{a t m}}{2 \pi i_{1}}=\frac{P_{a t m}}{2 \pi \cdot \operatorname{tg} \alpha_{1}}$, and the zone far 
from the well $\left(\frac{k h}{\mu}\right)_{2}=\frac{P_{a t m}}{2 \pi i_{2}}=\frac{P_{a t m}}{2 \pi \cdot \operatorname{tg} \alpha_{2}}$. From here $\Pi_{3}=\frac{\left(\frac{k h}{\mu}\right)_{2}}{\left(\frac{k h}{\mu}\right)_{1}}$. The ascending straight line of the zone far from the well of the reservoir cuts off the $x_{0}$, segment on the abscissa axis, according to which the complex piezoelectric parameter is calculated: $\frac{\mathfrak{x}}{r_{n}^{2}}=\frac{e^{-x_{0}}}{2.2458}$, where $k-$ the permeability coefficient of the reservoir, $\mathrm{m}^{2} ; h$ - effective reservoir power, $\mathrm{m} ; \mu-$ dynamic viscosity of oil in reservoir conditions, $\mathrm{Pa} \cdot \mathrm{s} ; i_{1}-$ the tangent of the angle of inclination of the line to the abscissa axis in the zone near the well of the reservoir.

Similarly, the gas hydrodynamicity of a remote reservoir zone $\left(\frac{k h}{\mu}\right)_{2}$ is determined by the formula: $\left(\frac{k h}{\mu}\right)_{2}=\frac{1}{4 \pi i_{2}}$, where $i_{2}-$ the tangent of the angle of inclination $\alpha_{2}$ of the straight line to the abscissa axis in the remote zone of the productive reservoir.

This implies the possibility of calculating the bottomhole plugging coefficient of the $\Pi_{3}$ formation, based on its definition.

Processing PRC method I.A. Charny or the final section of the PRC in coordinates $\lg \left(P_{\text {res }}^{2}-P_{\text {bot }}^{2}\right)=\alpha_{1}+\beta_{1} t$ (that is $\lg \left(P_{\text {res }}^{2}-P_{\text {bot }}^{2}\right)$ from $t$ than $\alpha_{1}$ - a segment of a line on the axis $\lg \left(P_{\text {res }}^{2}-P_{b o t}^{2}\right)$, and the tangent of the angle of inclination is equal to $\beta_{1}$, moreover $\beta_{1}=\frac{2.51 c e}{R_{k}^{2}}[3]$, is found the complex parameter $\frac{a}{R_{k}^{2}}$. Using both complex parameters $\frac{a}{r_{n}^{2}}$ and $\frac{a}{R_{k}^{2}}$ [13], one more complex parameter is determined $\ln \frac{R_{k}}{r_{n}}$, due to which the inflow equation is found to be the coefficient of linear resistance $A$ : $\ln \frac{R_{k}}{r_{n}}=2 \pi A\left(\frac{k h}{\mu}\right)_{1}$, and therefore the $B$ coefficient, if the inflow equation is solved with respect to $B$.

Thus, an equation of formation fluid inflow to the bottom of the well is obtained:

$$
\frac{P_{r e s}^{2}-P_{b o t}^{2}}{2 P_{a t m}}=A Q+B Q^{2}
$$

where $P_{\text {res }}-$ the reservoir pressure, $\mathrm{Pa} ; P_{b o t}-$ pressure at the bottom, $\mathrm{Pa} ; P_{a t m}-$ atmospheric pressure, equal to $0.1013 \cdot 10^{6} \mathrm{~Pa} ; Q$ - production rate from the reservoir.

Next, is found the summary radius of the well $[18,19]: r_{n}=\sqrt[\Pi_{3}]{e^{n}}$, where $n=\Pi_{3} \ln r_{c}-\left(\Pi_{3}-1\right) \ln \left(\frac{R_{k}}{r_{n}}\right)$. 
The piezo conductivity coefficient $\mathfrak{x}$, is determined by substituting the value of the combined radius $r_{n}$ in the formula for the complex parameter of the piezo conductivity $\frac{a}{r_{n}^{2}}$.

The formula $\psi=\frac{k}{m}=\frac{a \cdot \mu_{\text {res }}}{P_{\text {res }}}$ determines the ratio of permeability to porosity, where $\mu_{\text {res }}$ - the dynamic viscosity of the gas under reservoir conditions; $m$ - the porosity.

The conductivity of the reservoir $k h$ is determined by multiplying the gas-conductivity of the remote zone of the reservoir $\left(\frac{k h}{\mu}\right)_{2}$ by the dynamic viscosity of the gas in the reservoir $\mu_{\text {res. }}$

The reservoir capacity is calculated as follows: $m h=\frac{k h}{\psi}$.

An informative parameter $x_{0}{ }^{*}$ is found by the formula $x_{0}^{*}=\frac{k h}{2 \psi}$.

Is build a graphical dependence $2 x_{0}^{*} k=f(m k)$ processing an informative plot of which by the method of spline interpolation, is find $\operatorname{tg} \beta=\frac{h}{2}$. Having determined the effective reservoir power, it is possible to calculate the permeability of the reservoir $k$, by dividing the complex conductivity parameter $k h$ by the effective reservoir power $h$ and the porosity of the reservoir by dividing the reservoir $m h$ by the effective power $h$. Skin effect is determined by definition $S=\ln \frac{r_{c}}{r_{n}}$. The average pore diameter of the reservoir is determined by the formula $d_{\text {ave }}=\sqrt{32 \psi}$. The function of the product of capacitance and conductivity is found by expression $F=\psi(m h)^{2}$, and the function of the product of capacitance and permeability is $f=2 x_{0} \cdot k$.

In addition, it is possible to calculate the macro-roughness parameter of the rock $l$. Macro roughness parameter $l$ is calculated using the formula: $l=1 / \beta^{*}$, where $\beta^{*}-$ structural coefficient of tortuosity and the intermittent intersection of pore channels, which is calculated by the formula $\beta^{*}=\frac{63 \cdot 10^{6}}{\left(\frac{k}{m}\right)^{3 / 2}}$.

Find the ratio of the volume of production in atmospheric conditions to the volume of the same mass in reservoir conditions $\frac{V_{\text {atm }}}{V_{\text {res }}}$.

Recently, it has been possible to use the data obtained in the study of gas wells in one mode to calculate the preliminary value of the initial gas reserves $[1,20]$. This indicator is very important [18], because it gives an idea of the amount of production in the studied object.

\section{Research results as a spectrum of the obtained parameters}

To summarize the above, the solutions to the problem of determining a much larger volume of gas-hydrodynamic parameters of highly debit wells is stated; they were studied in nonstationary modes compared to the existing methodological options for processing PRC. 
And the nature of pressure changes in the reservoir and the intensity of its decline during well operation can also be analyzed according to the results of well research [16].

The following indicators have been calculated: gas-water presence in the subsurface zone $\left(\frac{k h}{\mu}\right)_{1}$; gas conductivity of outlying zone of layer $\left(\frac{k h}{\mu}\right)_{2}$; bottomhole blockage parameter $\Pi_{3}$; complex parameter the ratio of piezoelectricity to the squared summary radius of the well $\frac{c e}{r_{n}^{2}}$; complex parameter the ratio of piezo conductivity to the square of the radius of the well drainage contour $\frac{a}{R_{c}^{2}}$; the coefficient of the linear resistance flow equation $A$; the coefficient of the inertial resistance flow equation $B$; the flow equation $\frac{P-P}{2 P}=A Q+B Q^{2}$; reservoir productivity coefficient $K_{r}$; summary radius $r_{s}$; the circuit of drainage radius $R_{c}$; skin effect $S$; piezo conductivity coefficient $\propto$; permeability to porosity ratio parameter $\psi=\frac{k}{m}$; the function of the product of capacitance and conductivity $F$; reservoir capacity $m h$; reservoir conductivity $k h$; reservoir porosity $m$; reservoir permeability coefficient $k$; effective reservoir power $h$; collector average pore diameter $d_{\text {ave }}$; rock macro roughness parameter $l$, preliminary value of initial gas reserves.

\section{Conclusions}

So, thanks to the application of the proposed data processing method, it became possible to solve more complex problems of underground gas-hydrodynamics. On the other hand, this allowed the wider use of analytical approaches to solving problems. In addition, this makes it possible to use complex mathematical (integral, differential, integral-differential) calculation methods in their applied use. At the same time, the accuracy of calculations increased due to the elimination of approximate methods. It is impossible not to mention the efficiency of carrying out a large volume of calculations in the processing of actual material. And, very importantly, thanks to all these factors, sophisticated methods for interpreting the actual data from well surveys become available to a much wider circle of specialists involved in solving practical problems of gas hydrodynamics [20].

Slide of voting, the method of cutting gas-hydrodynamic parameters of the layers is unparalleled in visual or world practice. Importantly, and those methods, which have been fragmented, are attached to the methods for adjustment in the course of interpretation of results in the long term of gas wells of different productivity. In the past, the method was fragmented to produce low- and medium-value gas wells. The method, as it is the case in this publication, is actual for the semiconductor sills. It is just one of the most important factors in the theory of underground gas dynamics.

As for the informativeness of the method described in the software environment, it is not limited only to a significant amount of the calculated gas-hydrodynamic parameters, the elimination of the subjective factor when applying known methods, and the reduction of the time for processing well research materials. The most important thing in it is that it makes it possible to improve the research technology itself.

It is thanks to this that the direction for the rational development of the technological aspect of the study of gas and gas condensate wells becomes real, which will significantly reduce the cost and speed up the process. 
Due to this, the profitability of the oil and gas industry will increase and the quality of the environment will be preserved. That is, the goal will be achieved to reduce gas losses and time in the study of gas wells, there is an optimal optimization of geophysical tasks and geological tension in the whole.

\section{References}

1. Akulshin, O., Solovyov, V., Kondrat, R., \& Roy, N. (2016). Analytical determination of gashydrodynamic parameters change of productive layer is in the process of his development. Collection of scientific labours is the Prykarpattya announcer NTSH, 1(33), 167-174.

2. Marchenko, D.A. (2018). Analysis of the results of hydrodynamic studies of wells. In Materials of the International Scientific-Practical Conference "The Concept of Sustainable Development of Science in Modern Conditions" (pp. 20-24). Kazan, Russian Federation.

3. Khisamov, R., Suleismanov, E., Farkhullin, R., Nikashev, O., Gubaidullin, A., Ishkaev, R., \& Khusainov, V. (2000). Hydrodynamic studies of wells and methods of processing measurement results. Moscow, Russian Federation: JSC VNIIOENG, 228 p.

4. Klimov, V., Savenok, O., \& Leshkovich, N. (2017). Increase of reliability of geophysical methods in directional and horizontal wells. Scientific and Technical Journal "Ingener-Oilman", 33-37.

5. Koval, V., \& Khomyn, O. (2016). A comprehensive approach to determining the nature of the saturation of the productive horizon. Oil and Gas Industry of Ukraine, 9-13.

6. Koval, V.I. (2016). Application of a modern approach to the estimation of initial hydrocarbon reserves at the saturation pressure limit. Scientific Journal Science Rise, 6-13.

7. Lapshin, V., Minakov, I., \& Uvarov, D. (2015). Interpretation of the results of hydrodynamic studies of wells (with a steady filtration mode). Scientific and Technical Collection of News of Gas Science, 36-41.

8. Roy, M.M. (2018). The method of steady filtration as one of the hydrodynamic studies of productive horizons. Proceedings of the All-Ukrainian Scientific and Technical Conference "Oil and Gas", 47-49.

9. Nazarov, A.V., \& Durkin, S.M. (2014). Review of modern method of interpretation of well test with fractured porous reservoirs. Oil and Gas Business, (6), 392-407. https://doi.org/10.17122/ogbus-2014-6-392-407

10. Petrushin, E., Savenok, O., \& Harutyunyan, A. (2017). Estimation of reliability of a reservoir parameter determination technique according to the data of a horizontal well investigation. Nauka i Tekhnika v Gazovoy Promyshlennosti, 62-71.

11. Liakhu, M.V., \& Liakhu, R.M. (2016). Forecast estimation of oil and gas reserves by development curves. In Materials of the International Scientific and Technical Conference "Prospects for Increasing the Resource Base of Oil and Gas Energy" (pp. 74-76).

12. Roy, M., \& Akulshin, O. (2019). Current stress of optimization process up to the degree of gas and gas condensate wells. Problems and Prospects of Oil and Gas Production, 45-60. https://doi.org/10.32822/naftogazscience.2019.03.045

13. Escobar, F.H., Cortes, N.M., Pabón, O.D., \& Hernández, C.M. (2016). Pressure transient analysis for off-centered horizontal wells in homogeneous anisotropic reservoirs with closed and open boundaries. Journal of Engineering and Applied Sciences, 11(17), 10156-10171.

14. Roy, M.M. (2017). One of methods of preliminary estimate of size of openings gas stocks. Science Announcer IFNTUNG, (2), 7-12.

15. Zhao, Y.L., Escobar, F.H., Hernandez, C.M., \& Zhang, C.P. (2016). Performance analysis of a vertical well with a finite-conductivity fracture in gas composite reservoirs. Journal of Engineering and Applied Sciences, 11(15), 8992-9003.

16. Solovyov, V.V., \& Roy, M.M. (2015). The study of stress-strain state of the wellbore with the content of plastic rocks. Metallurgical and Mining Industry, 555-558. 
17. Roy, M.M. (2017). A research method of highly productive gas and gas-condensate wells is at the non-stationary filtration mode. Patent of Ukraine \#121860. Kyiv, Ukraine.

18. Sudakov, A., Dreus, A., Kuzin, Y., Sudakova, D., Ratov, B., \& Khomenko, O. (2019). A thermomechanical technology of borehole wall isolation using a thermoplastic composite material. E3S Web of Conferences, (109), 00098. https://doi.org/10.1051/e3sconf/201910900098

19. Bahniuk, M., Vladyka, V., Dmyshko, O., Dorokhov, M., Bodlak, V., \& Kozak, L. (2019). Filtration properties of reservoir rocks as the basis for estimating drained gas reserves. In Materials of the UI of the International Geological Forum "Actual Problems and Prospects of Geology Development: Science and Production” (pp. 21-25). Odessa, Ukraine.

20. Shaganenko, E.S. (2016). Basic principles of well testing. Priority Research Areas: From Theory to Practice, 205-210. 